\title{
ANALYSIS OF THE INFLUENCE OF THE INPUT PARAMETERS ON THE EFFICIENCY OF THE OPERATION OF THE DETANDER GENERATOR UNIT IN THE GAS NETWORK SYSTEM OF THE REPUBLIC OF UZBEKISTAN
}

\author{
Mukolyants Arsen Artyomovich ${ }^{1}$, Buranov Mardon Davronovich ${ }^{1}$, Sotnikova Irina Vladimirovna ${ }^{1}$, Azimova Munira Muminovna, ${ }^{1}$ \\ ${ }^{1}$ Uzbekistan, Tashkent State Technical University, Docent
}

\begin{abstract}
The article is devoted to the generally recognized dilemma of using secondary energy resources in the transportation and distribution of natural gas. At stations where throttle devices are used, excessive gas pressure as the main component of secondary energy resources for technological processes is practically not used. Currently, the replacement of throttle devices with turbo-expander units is determined by energy and economic efficiency. This is due to the fact that the use of excess gas pressure in the turbo expander both at gas distribution stations and at compressor stations of gas pipelines without preheating has not yet been widely used. Expander-generator technology is probably one of the most effective technologies for reducing the consumption of fuel and energy resources. The combination of expander-generator units with heat pump units contributes to the creation of highly efficient power generating complexes that can generate electricity without burning fuel. Expansion of high-pressure natural gas at gas distribution stations is one of the technologies for generating electricity without combustion. To determine the share of electric energy supplied to the electric network based on the expander-generator set in the gas supply system, an analytical dependence was determined. Based on this, an arithmetic model of the installation with single-stage expander-generator units and steam-compression heat pump units is proposed. All data will be presented in detail in this article.
\end{abstract}

Keywords: main gas pipeline, transported natural gas, gas distribution station, process differential pressure, expander generator, heat pump installation, power generation.

\section{Introduction}

One of the most significant problems of our time, The problem of energy conservation, being one of the most important in all developed countries, is becoming especially acute in Republic Uzbekistan. And this is not accidental, because with the growth of the economy and the standard of living of the population, the need for energy has also increased. So, lately, the generating capacities of the country's system have noticeably increased. A $300 \mathrm{MW}$ power unit at the Novo-Angren Thermal Power Station (TPS), a 800 MW unit at the Talimarjan TPP were commissioned, a project to expand the Navoi TPS with the construction of a gasvapor unit (GVU) with a capacity of $478 \mathrm{MW}$ was implemented, and a cogeneration gas turbine unit was introduced at the Tashkent Heat and Power Stantion with a capacity of $27 \mathrm{MW}$.

One of the promising approaches to save energy is the use of expander-generator units (EGU) for the production of electricity through the use of technological pressure difference of the transported natural gas. Nonetheless, to date, no practical measures have been taken for the large-scale and effective practical application of this technology in the Central Asian republics, including the Republic of Uzbekistan. Respectively, for uninterrupted power supply of the linear part of gas pipelines, gas meters at gas distribution stations (GDS), gas distribution points
(FRP) and other gas supply facilities, the authors consider it more than appropriate to use (EGU) to generate clean electricity through the use of compressed completely natural gas energy.

The effectiveness of the EGU depends on the method of heating the gas in front of the expander.

In [1-2], various methods of gas heating using EGU and the issues of determining the energy efficiency of using EGU are considered. It is shown that when choosing a gas heating system, it is necessary to take into account how gas is used after expansion in the expander, as well as how changing the gas parameters affects the performance of gas-consuming equipment.

In [3-4], the use of EGU in industry is considered, and the distinguishing characteristics of kinetic and volumetric machines are given.

In [5-7], the possibility of using EGU in boiler rooms is described. Various options for heating the gas in front of the EGU are considered: direct network water, flue gases, or using a heat pump installation, to ensure the operation of which part of the electricity generated by the EGU is used. The advantages and disadvantages of each of the considered methods of gas heating are revealed, an exergy analysis of the proposed schemes is carried out. The influence of EGU on the energy efficiency of boiler houses under variable operating conditions is analyzed and an economic assessment of the use of EGU in boiler rooms is given. 
This article discusses the main indicators of the installation, in which the gas is heated using a heat pump [8-10].

Fragments of the installation for research are presented in Fig. 1a, b,c,d.

\section{Research methods and results}

The work and indicators of EGU are considered in two versions:

1) Turning on of EGU without changing the gas consumption for gas consuming equipment;

2) Turning on of EGU affects the gas flow to gas consuming equipment and varies in proportion to the change in the available heat of the gas, taken equal

$$
Q_{\mathrm{O}}^{\mathrm{W}}=Q_{\mathrm{L}}^{\mathrm{W}}+h_{\mathrm{G}}-h^{0},
$$

where $Q_{\mathrm{L}}^{\mathrm{W}}$ - lower calorific value of the gas, $h_{\mathrm{G}}, h^{0}-$ gas enthalpy at given temperature and pressure and at $0^{0} \mathrm{C}$ and pressure $0.1 \mathrm{MPa}$, respectively.

In option 2), the specific change in the gas flow rate $q_{\mathrm{SP}}$ to the gas-consuming unit at EGU start-up is also determined:

$$
q_{\mathrm{SP}}=\frac{\Delta G_{\mathrm{G}}}{N_{\mathrm{UNIT}}},
$$

where: $N_{\text {UNIT }}$ - net power delivered to the power grid;

$$
\Delta G_{\mathrm{G}} \text { - change in gas flow. }
$$

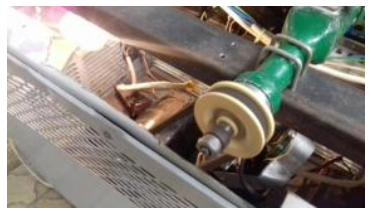

a

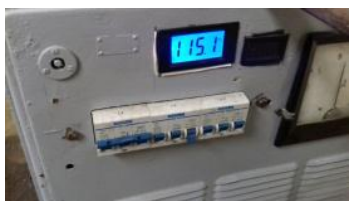

c

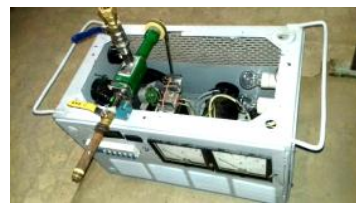

b

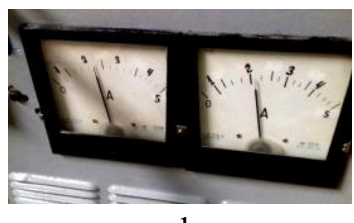

d
Fig.1. Fragments of the installation for research

In Fig. 2. the scheme of gas heating before EGU by low-grade heat using a heat-pumping unit (HPU) is shown. A part of the energy generated by EGU is used to drive the HPU compressor.

The performance parameters of this unit are determined by selection of a refrigerant which provides the required gas temperature.

Let's investigate the case when a change in the enthalpy of gas at the inlet to a gas-consuming installation does not cause a change in gas flow.

Due to the fact that the change in gas flow rate to a gas-consuming installation $\Delta G_{\mathrm{G}}=0$, then the specific change in gas flow rate to generate electricity at the unit in Fig. $2 q_{\mathrm{SP}}=0$.

The amount of heat supplied to the gas, $Q_{\text {SUP }}$, is equal to:

$$
Q_{\mathrm{SUP}}=G_{\mathrm{G}} \cdot\left(h_{1}-h_{0}\right),
$$

where: $G_{\mathrm{G}}$-gas flow; $h_{0}, h_{1}$ - gas enthalpy before heat exchanger 3 (Fig.2) and before expander, respectively.

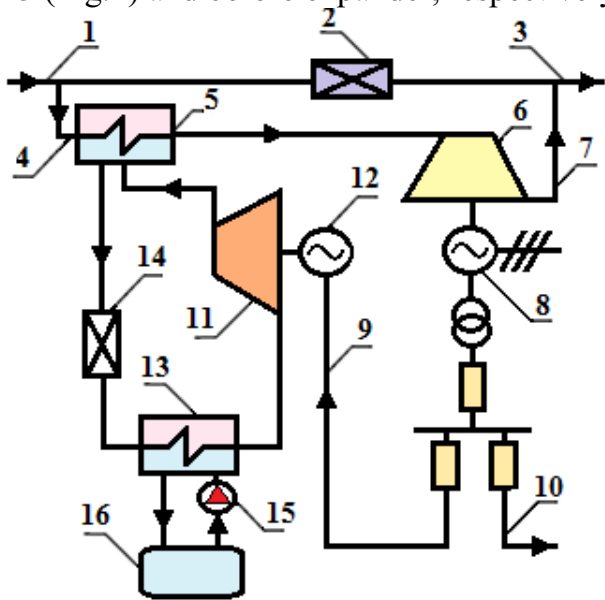

Fig.2. The technological scheme of the installation with an expander-generator unit and a heat pump for heating gas in front of the expander:

1 - high pressure gas pipeline; 2 - throttling device; 3 - low pressure gas pipeline; 4 - high pressure gas supply to the expander; 5 - gas heat exchanger in front of the expander; 6 turboexpander; 7 - low pressure gas pipeline at the outlet of the expander; 8 - electric generator; 9 - line for supplying electricity to an electric motor drive a compressor; 10 - line for supplying electricity to the power grid; 11 - compressor; 12 - electric motor - compressor drive; 13 - evaporator; 14 throttling device; 15 -pump of heat carrier supply of heat of low temperature potential; 16 - heat source of low temperature potential.

During the calculations, the following initial data were taken.

1. Absolute inlet / outlet pressures for technological gas pressure reduction stations (in $\mathrm{MPa}$ ):

- for GDP - $0.8 / 0.2 ; 1.0 / 0.2 ; 1.2 / 0.2$;

- for GDS $-4.0 / 1.5 ; 5.0 / 1.5 ; 6.0 / 1.5$.

2. Gas temperature at the inlet to the station of technological pressure reduction $-0^{\circ} \mathrm{C}$.

3. Gas consumption $-10,000 \mathrm{Nm}^{3} / \mathrm{h}$.

4. A reservoir with the parameters of the coolant at the inlet to the HPU evaporator $-+5^{\circ} \mathrm{C}$, and at the outlet from it $-+3^{\circ} \mathrm{C}$ was selected as a source of lowgrade heat.

5. Set gas temperatures at the outlet of the HPU condenser $-50 ; 60 ; 70$ and $80^{\circ} \mathrm{C}$.

6. The maximum heat that can be supplied in the heat exchanger after the HPU condenser is limited by the condition:

- when the unit is operating without gas heat recovery after the expander, the heat supplied in the heat exchanger in each operating mode should not be much higher than the heat supplied in the HPU condenser.

7. Characteristics of EGU:

- internal relative efficiency of the expander 0.748 ; - generator efficiency - 0.98 .

Power is required for heat pump installation

$$
N_{\mathrm{C}}=\frac{Q_{\mathrm{SUP}}}{\varphi}=\frac{G_{\mathrm{G}} \cdot\left(h_{1}-h_{0}\right)}{\varphi},
$$

where $\varphi$ - heat transfer coefficient. 
The fraction of EGU power $\alpha_{\mathrm{DR}}$, spent on compressor drive is determined by the following expression:

$$
\alpha_{\mathrm{DR}}=\frac{N_{\mathrm{C}}}{N_{\mathrm{EGU}}}=\frac{\left(h_{1}-h_{0}\right)}{\left(h_{1}-h_{2}\right) \cdot \varphi},
$$

where $h_{2}$ - gas enthalpy after expander.

Dependence of the fraction of EGU power spent on compressor drive on the temperature of gas heating before the expander at different initial gas pressures is shown in Fig. 3a and heat transformation coefficients are shown in Fig. 3b.

The fraction of power $\alpha_{\text {GRID }}$ supplied to the power grid will be equal to

$$
\alpha_{\mathrm{GRID}}=\frac{N_{\mathrm{EGU}}-N_{\mathrm{C}}}{N_{\mathrm{EGU}}}=\frac{(\varphi-1)}{\varphi}+\frac{\left(h_{0}-h_{2}\right)}{\varphi \cdot\left(h_{1}-h_{2}\right)} .
$$

When $h_{0}=h_{2} \quad \alpha_{\mathrm{GRID}}=\frac{(\varphi-1)}{\varphi}$, i.e. $\alpha_{\mathrm{GRID}}$ depends only on the parameters of the heat pump, the useful power $N_{\text {UNIT }}$ will be equal to:

$$
N_{\mathrm{UNIT}}=N_{\mathrm{EGU}}-N_{\mathrm{C}}=G_{\mathrm{G}}\left(h_{1}-h_{2}\right) \cdot\left(1-\alpha_{\mathrm{DR}}\right) .
$$

If $h_{0} \neq h_{2}$, gas flow to the gas-consuming installation changes, and the formula for determining the useful power of the unit will be as follows:

$$
N_{\mathrm{UNIT}}=G_{\mathrm{G}} \cdot \frac{Q_{\mathrm{L}}^{\mathrm{W}}+h_{0}-h^{0}}{Q_{\mathrm{L}}^{\mathrm{W}}+h_{2}-h^{0}} \cdot\left(h_{1}-h_{2}\right) \cdot\left[1-\frac{\left(h_{1}-h_{0}\right)}{\left(h_{1}-h_{2}\right) \cdot \varphi}\right] \text {. }
$$

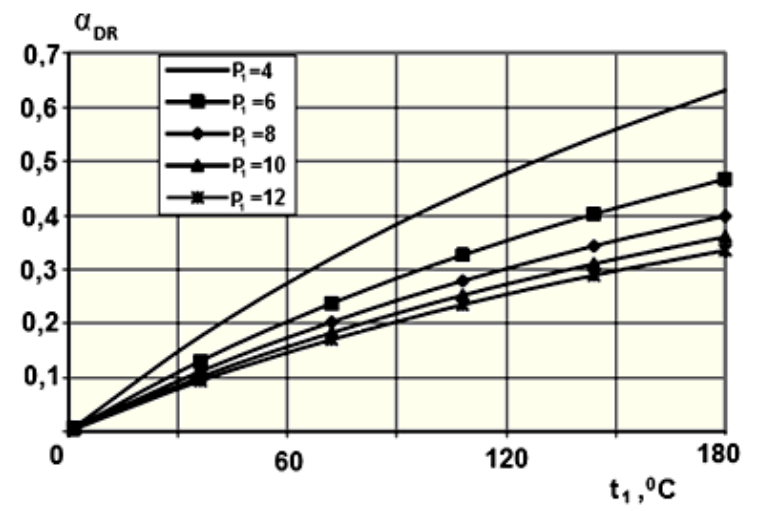

a) at various gas pressures $(\varphi=4)$

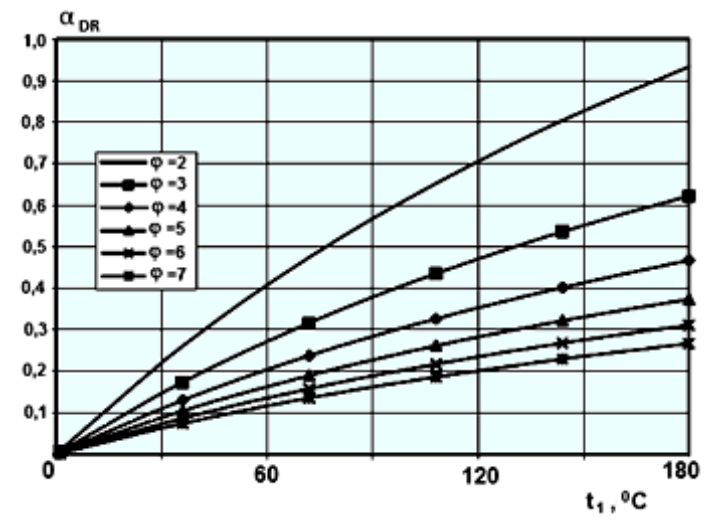

b) for various $\varphi\left(p_{1}=6 \mathrm{~kg} / \mathrm{cm}^{2}\right)$

Fig.3. fraction of EGU power spent on HPU compressor drive
The change in gas flow can be determined from the following expression:

$$
\Delta G_{\mathrm{G}}=G_{\mathrm{G}} \cdot \frac{h_{0}-h_{2}}{Q_{\mathrm{L}}^{\mathrm{W}}+h_{2}-h^{0}},
$$

and specific change in gas flow for electricity generation:

$$
q_{\mathrm{SP}}=\frac{1}{Q_{\mathrm{L}}^{\mathrm{W}}+h_{0}-h^{0}} \cdot \frac{h_{0}-h_{2}}{h_{1}-h_{2}} \cdot \frac{1}{1-\frac{\left(h_{1}-h_{0}\right)}{\left(h_{1}-h_{2}\right) \cdot \varphi}} .
$$

The graphs in Fig. 4 show the results of calculating the dependence of specific change in gas flow on the temperature of gas heating before the expander for various $\varphi$ (Fig. 4a) and initial gas pressures (Fig. 4b).

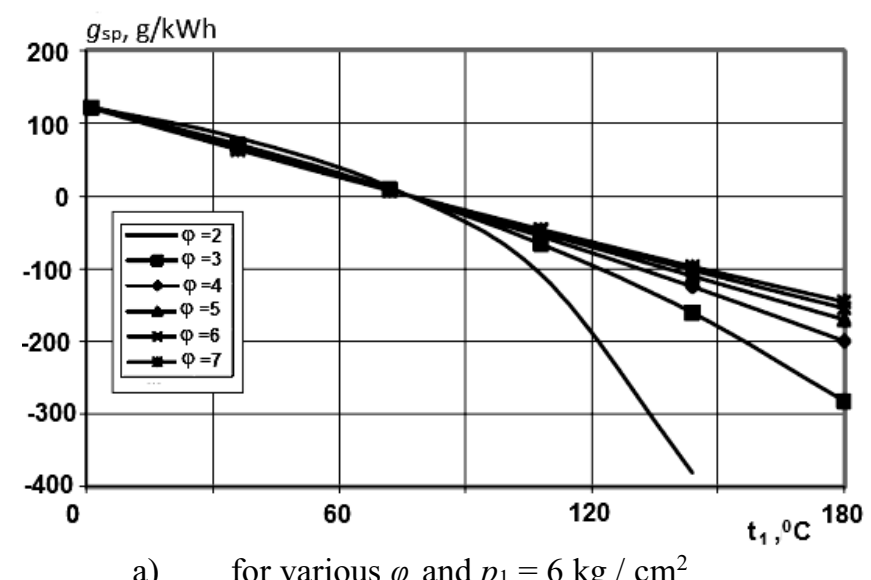

a) for various $\varphi$ and $p_{1}=6 \mathrm{~kg} / \mathrm{cm}^{2}$

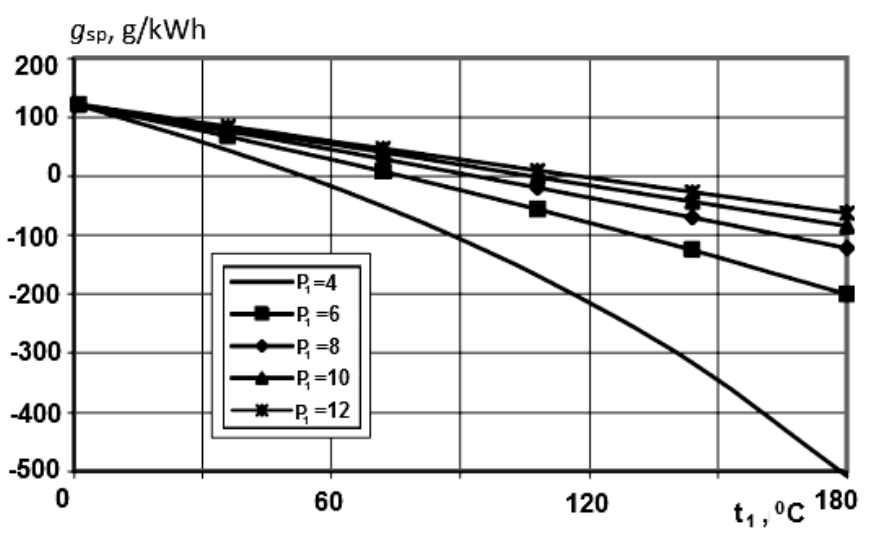

b) for various $p_{1}$ and $\varphi=4$

Fig.4. Dependence of specific change in gas flow on the temperature of gas heating

It should be noted that if $h_{0}<h_{2}$, then the gas flow rate to the gas-consuming installation will decrease, and when attributing the change in gas flow rate to EGU, the specific change in gas flow rate will be less than 0 .

The mathematical model of the unit with singlestage expander-generator units and vapor compression heat pump units is presented as follows.

The object of simulation is a fuel-free installation for generating electricity on the basis of an expandergenerator unit and a steam compression heat pump, shown in Figure 1. The main elements of the simulation object are: expander 6 and generator 8 , evaporator 13 , compressor 11 with electric motor 12 for its drive and a capacitor 5 of HPU, gas pipelines 1 
and 3 of high and low pressure, a source of low potential heat 16 .

\section{Heat pump unit}

Mathematical description of HPU evaporator:

- heat transferred by the low potential heat carrying medium to the refrigerant:

$$
Q_{10}=G_{\mathrm{LPHS}} \cdot\left(h_{11}-h_{10}\right) \cdot \varphi
$$

- heat received by the refrigerant from a low potential source:

$$
Q_{10}=G_{\text {ref }} \cdot\left(h_{6}-h_{9}\right)
$$

Mathematical description of HPU condenser:

- heat transferred by the refrigerant to the transported gas:

$$
Q_{3}=G_{\text {ref }} \cdot\left(h_{7}-h_{8}\right) \cdot \varphi
$$

- heat received by the transported gas from the refrigerant:

$$
Q_{3}=G_{\mathrm{g}} \cdot\left(h_{4}-h_{3}\right) \text {. }
$$

Equations for determining the flow rate of the refrigerant in the HPU circuit:

or

$$
G_{\mathrm{ref}}=\frac{Q_{3}}{\left(h_{7}-h_{8}\right) \cdot \eta_{\mathrm{HE}}}
$$

$$
G_{\text {ref }}=\frac{Q_{10}}{\left(h_{6}-h_{9}\right)}
$$

Power consumed by HPU compressor:

$$
N_{8}=\frac{G_{\mathrm{ref}} \cdot\left(h_{7}-h_{6}\right)}{\eta_{\mathrm{EM}}} \text {. }
$$

\section{Expander-generator unit}

Power generated by EGU:

$$
N_{2}=G_{\mathrm{g}} \cdot\left(h_{4}-h_{5}\right) \cdot \eta_{\mathrm{EM}}
$$

or

$$
N_{2}=G_{\mathrm{g}} \cdot \frac{k}{k-1} \cdot R_{\mathrm{g}} \cdot T_{4} \cdot z_{4} \cdot\left(1-\left(\frac{p_{5}}{p_{4}}\right)^{\frac{k-1}{k}}\right) \cdot \eta_{\mathrm{o} i} \cdot \eta_{\mathrm{EM}} .
$$

Gas temperature at EGU outlet:

where $k$ is the adiabatic coefficient for the transported gas.

Electricity supplied to the power grid:

$$
N_{7}=N_{2}-N_{8} \text {. }
$$

Share of electricity supplied to the power grid:

$$
\alpha=\frac{N_{2}-N_{8}}{N_{2}} \text {. }
$$

\section{Algorithm for calculating installation parameters with single-stage EGU and vapor compression HPU.}

1. Gas temperature at EGU outlet is calculated from the known enthalpy and pressure:

$$
t=f(p, h)
$$

2. Gas temperature at EGU inlet is calculated from the equation:

$$
T_{4}=T_{5} / \frac{z_{4}}{z_{5}} \cdot\left[\eta_{o i} \cdot\left(\left(p_{4} / p_{5}\right)^{\frac{k-1}{k}}-1\right)+1\right]
$$

Coefficient $z_{4}$ in the first approximation is set equal to

$z_{5}$, then the calculation is performed by the method of successive approximations.

3. Power generated by the EGU is calculated from the expression:

$$
N_{2}=G_{\mathrm{g}} \cdot \frac{k-1}{k} \cdot R_{\mathrm{g}} \cdot T_{4} \cdot z_{4} \cdot\left(1-\left(\frac{p_{4}}{p_{5}}\right)^{\frac{k-1}{k}}\right) \cdot \eta_{o i} \cdot \eta_{\mathrm{EM}} .
$$

4. Gas enthalpy at the inlet and outlet of the gas preheating heat exchanger is calculated:

$$
h=f(p, t) \text {. }
$$

5. Thermal energy required to heat the gas to a predetermined temperature is calculated from the equation:

$$
Q_{3}=G_{\mathrm{g}} \cdot\left(h_{4}-h_{3}\right) .
$$

6. Refrigerant temperature at HPU compressor outlet is calculated:

$$
t_{7}=t_{4}+\delta_{1} \text {. }
$$

7. Refrigerant temperature HPU condenser outlet is calculated:

$$
t_{8}=t_{3}+\delta_{2} \text {. }
$$

8. Refrigerant temperature HPU evaporator outlet is calculated:

$$
t_{6}=t_{11}-\delta_{3} .
$$

9. Refrigerant parameters at all points in the HPU circuit are calculated:

$$
\begin{gathered}
h_{6}=f\left(t_{6}\right), p_{6}=f\left(t_{6}\right), s_{6}=f\left(t_{6}\right) \\
s_{7}^{\text {id }}=s_{6}, p_{7}=f\left(t_{7}, s_{7}^{\text {id }}\right), h_{7}^{\text {id }}=f\left(t_{7}, s_{7}^{\text {id }}\right), h_{7}=h_{6}+\frac{h_{7}^{\text {id }}-h_{6}}{\eta_{o i}}
\end{gathered}
$$

$$
\begin{gathered}
h_{8}=f\left(t_{8}, p_{8}\right), p_{8}=p_{7} \\
h_{8}=h_{9} .
\end{gathered}
$$

10. Refrigerant flow rate in the HPU circuit is calculated:

$$
G_{\mathrm{ref}}=\frac{Q_{3}}{\left(h_{7}-h_{8}\right) \cdot \eta_{\mathrm{HE}}} .
$$

11. Power required to drive the HPU compressor is calculated:

$$
N_{8}=\frac{G_{\mathrm{ref}} \cdot\left(h_{7}-h_{6}\right)}{\eta_{\mathrm{EM}}} .
$$

12. Flow rate of the heat-carrying medium from the low potential heat source is calculated:

$$
G_{\mathrm{LPHS}}=\frac{G_{\mathrm{ref}} \cdot\left(h_{7}-h_{9}\right)}{\left(h_{11}-h_{10}\right) \eta_{\mathrm{HE}}} .
$$

13. The share of electricity supplied to the power grid is calculated:

$$
\alpha=\frac{N_{2}-N_{8}}{N_{2}} .
$$

Figure 5 shows a graph of the dependence of the share of electricity supplied to the network on the heat supplied from the wind turbine at different gas temperatures at the outlet of the HPU condenser for a pressure ratio of $0.8 / 0.2 \mathrm{MPa}$. 


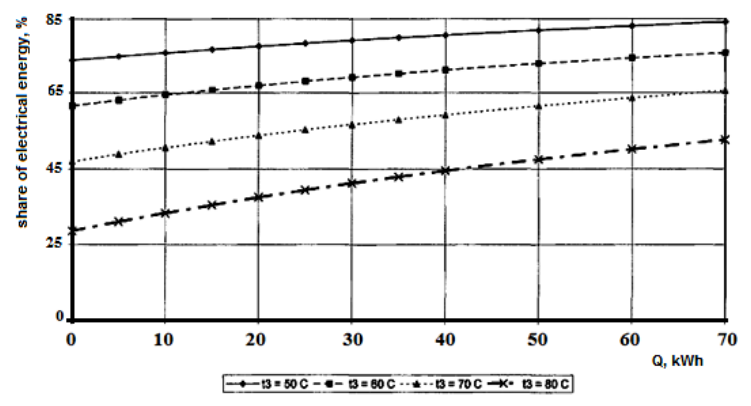

Fig. 5. Dependence of the share of electricity supplied to the network on the heat supplied from the wind turbine at different gas temperatures at the outlet of the HPU condenser, for a pressure ratio of $4.0 / 1.5 \mathrm{MPa}$

\section{Conclusion}

Thus, from the above graph it can be seen that an increase in the gas temperature after the HPU condenser leads to a decrease in the share of electricity supplied to the network. This is explained by a more intensive increase in the required electric power of the heat pump unit with an increase in the gas temperature at the outlet of the HPU condenser in comparison with the increase in the power of the EGU associated with an increase in the gas temperature before the expander.

Based on all of the above, we can come to the following conclusion: the obtained dependences make it possible to calculate the useful power of a EGU, in which HPI is used to heat the gas before the expander, and the use of a heat pump installation to heat the gas before the expander allows not only to obtain electricity without burning additional gas, but also to reduce gas consumption at the gas-consuming installation due to increase the physical heat of the gas.

\section{References}

1 A A Mukolyants, M D Buranov, I V Sotnikova and $\mathrm{H}$ F Makhmudov. Operation analysis of expander-generator unit at a gas distribution station. Journal of Physics: Conference Series. 2020. Journal of Physics: Conference Series 1515 022053 https://doi:10.1088/17426596/1515/2/022053.

2 Agababov V 2004 J. News of Higher Education Institutions, Energy issues B 7 50-60.

3 Buranov M., Mukolyants A. and Sotnikova I. 2019 J. Phys.: Conf. Ser. 1399055038 doi:10.1088/1742-6596/1399/5/055089.

4 Belousov A. 2016 J.Oil and Gas Technologies B 3 51-55

5 Agababov V., Koryagin A., Utenkov V. and Khaymer Yu. 2000 J.Gas-Erdgas gwf. B 9610 615.

6 R. Gambhire 2014 J. International journal of innovative research in science B 3 293-300.

7 Repin L 2004 J.Energy Saving B 3 34-39.

8 Prilutsky A 2008 J. Chemical, Oil and Gas Engineering B 3 26-31.

9 Mukolyants A.A., Sotnikova I.V., Ergasheva D.K., Karimova N.E Study of efficiency of schemes of fuel-free units of electric power generation in a gas supply system. International Journal of Advanced Science and Technology. Vol. 29, No. 7, (2020), pp. 9269-9273

10 Mukolyants A.A., Buranov M.D., Sotnikova I.V., Makhmudov H.F. The expander-generator unit at a gas distributing station of magistral gas pipeline. The collection includes 16th the International Scientific and Practical Conference "Science and Socienty" by SCIEURO in London 23-28. 